\title{
AUDIOVISUAL CONTENT IN FOREIGN LANGUAGE TEACHING
}

\author{
Xiaohui Sun, D.Ph. \\ Weifang University, China \\ xiaohuisun@wfu.edu.cn \\ ORCID ID: 0000-0002-4723-5347 \\ Branko Medic, D.Sc. \\ Manchester University, the United Kingdom \\ medic.tesol@gmail.com \\ ORCID ID: 0000-0002-1937-0947
}

\begin{abstract}
Following the recent dominance of videos as the most preferred content type among young learners, this research paper sets out the aim to investigate how audiovisual content can be used in foreign language teaching. The focus is on subtitling and captioning as two strategies often criticised by practitioners, yet widely adopted in the foreign language classroom. Empirical data is deployed to discuss both advantages and disadvantages of videos in the educational context. Finding s are relevant for foreign language professionals who are willing to gain critical awareness on the latest Web 2.0 developments and to mindfully implement videos in class.
\end{abstract}

1

\section{. INTRODUCTION}

The increasingly wide-spread adoption of computer assisted language learning (CALL) has been giving rise to opportunities, but also introducing new challenges (Conole and Alevizou, 2010). Students are no longer only consuming information on the Internet. They are also connected with others. Web 2.0 is the term used to acknowledge the shift from the passive Web to its social use, which allows learners to interact and collaborate, being actively engaged in content (Alexander and Levine, 2008).

Since 2005, Internet applications have penetrated the discourse of traditional teaching and learning. Students often turn to Web 2.0 solutions to gather information and samples for real-life social interactions, as such opportunities are often unavailable in the traditional classroom (Garcia Mayo and Pica, 2000). Specific technologies that become popular among pupils and teachers include social networking sites, blogs, wikis, social bookmarking, and videos. Among them, videos are perhaps most accessible, since video-sharing platforms such as YouTube have grown to a major source of entertainment in leisure time (Merkt, et al., 2011).
Personally, it has been astounding to observe the evolution of modalities, triggered by Web 2.0. Text has been overshadowed by images, and images - by videos. Today, the most preferred content among young people is in the video format (Mintel, 2016). Nearly 70\% watch videos on streaming platforms such as YouTube and Netflix. These are the most popular Web 2.0 applications among teens and tweens, way beyond social networking sites like Facebook and Instagram (Mintel, 2017).

This makes videos crucial for instructors, aiming to reach young learners (Tarchi, Zaccoletti and Mason, 2021). They have been increasingly deploying videos as an educational medium, often accompanied by captions or subtitles. Indeed, it is generally acknowledged in literature that videos are more effective than text for numerous learningrelated aspects (Tarchi, Zaccoletti and Mason, 2021). However, for language students at the vocational college, videos might bring unexpected troubles, such as poor comprehension effort or lack of control on the information flow (Caspi, Gorsky and Privman, 2005; Merkt, et al., 2011). 
With this research paper, the aim is to puzzle out how videos can be used in foreign language teaching. By critically reviewing academic literature, a professional might reach own conclusions on what will work best for young students.

\section{A review of available sources}

Videos can be defined as the "the selection and sequence of messages in an audio-visual context" (Canning-Wilson and Wallace, 2000). Some videos might be too difficult for beginners with basic foreign language skills. Adding onscreen transcription of the dialogue, i.e. captions, or its translation in the language of the viewer, i.e. subtitles, can make content more comprehensible (Danan, 2004).

Instructors have been increasingly assigning tasks that require learners' efforts to study a video, obtained online (Tarchi, Zaccoletti and Mason, 2021). Alhamami (2013) specifically investigated how instructor-created YouTube videos are used as complete language learning lessons. He suggests that such an approach reveals the efficiency power of technology in education. Most teachers, however, do not develop their own audiovisual material. They use videos, already available on the Web, to supplement the course curriculum. The majority of videos are using text aid, which requires the non-native speaker to process information in the target language, and/or use the subtitles in their mother tongue (Tarchi, Zaccoletti and Mason, 2021).

Research on comprehension and knowledge acquisition from videos has a long tradition. Mayer's Cognitive Theory of Multimedia Learning (2002) is one of the most influential to explain these processes. Mayer suggests that students use two channels for information processing: the visual-pictorial and the auditory-verbal. So, when pupils are exposed to a subtitled foreign language video, for example, they pick relevant words from the subtitles, then they pick relevant images from the visuals, and organise them into a coherent verbal/pictorial whole (Mayer, 2002).

Interestingly, many tutors argue that reading is most effective for learning new vocabulary. They explain that lower-frequency words in particular cannot be easily derived from video material (Arndt and Woore, 2018). However, the combination of videos and text is found to be more effective for information acquisition than using text alone (e.g. Alley et al., 2014; Wannagat et al., 2017). That is because attention is improved (Alley, et al., 2014), information processing is easier and less burdening in multimedia environments (Mayer, 2002), and videos have greater power to elicit emotional responses (Yadav, et al., 2011). As for incidental vocabulary learning, Arndt and Woore (2018) busted the myth that reading text is more useful than watching videos. Web logs (blogs) have relatively the same effects as video blogs (vlogs) (Arndt and Woore, 2018).

A considerable amount of studies highlight the benefits of video instruction in foreign language classes. Among them, the results by Hanley, Herron and Cole (1995) suggest that English speakers learning French are positively influenced by the richness of the context, which in turn results in extensive listening. Canning-Wilson (2000) found that pupils like learning the target language through videos, and they favour entertaining or action videos at the expense of documentaries. Kabooha and Elyas (2012) recruited a sample of Saudi females, studying English as a foreign language (EFL) with or without YouTube videos. Findings revealed that those exposed to videos outperformed the non-exposed in terms of vocabulary acquisition. Moreover, respondents generally reported positive attitudes towards YouTube material, and found it attractive and interesting. Likewise, Pisarenko (2017) used a control and intervention group to measure the impact of videos among Russianspeaking high-school EFL learners. He confirmed that videos are effective for both knowledge acquisition and personality development.

On a less positive note, working with videos might be complex for students and time-consuming for teachers (Pisarenko, 2017). It goes without saying that people process information in different ways (Canning-Wilson and Wallace, 2000). For some, it would be difficult to simultaneously perceive phonetic, video, lexical, cultural, grammatical information (Pisarenko, 2017). To make comprehension easier, audiovisual material can be enhanced with captions or subtitles.

Significantly less studies specifically focus on the use of captioning and interlingual subtitling to accompany video material. Perhaps the most-cited advantage of text aid is improved comprehension (e.g. Markham 1989; Garza, 1991). Captions in particular are also praised for bridging the gap between reading and listening competence (Garza, 1991) and learning of 
unknown words and phrases (Chai and Erlam, 2008; Winke, Gass and Syodorenko, 2010).

Vocabulary memorisation also appears to be enhanced with captions, but with subtitles, the extent of this benefit is debated. Moreover, the effect of captions and subtitles cannot be treated in isolation from all other variables, related to video watching in class, including kinesic behaviour and the semantic match between video and audio (Bianchi and Ciabattoni, 2008). What also matters is the level of learners. For example, beginner and lower level students normally have difficulties in understanding native speakers in videos. So, with or without subtitles, their comprehension progress is supposed to be slower. On the other hand, advanced students are likely to benefit more from captioned videos, and report greater level of comprehension with text aid (Mohsen, 2015).

Danan (2004) suggests that captioning and subtitling are undervalued strategies, and "language teachers themselves tend to be openly hostile to their use" (p. 67). Accompanying text is seen as distracting by tutors. According to them, learners are encouraged to only rely on it, instead of paying attention to spoken language (Danan, 2004). Contrary to this concern, Chai and Erlam (2008) confirmed in their qualitative study with 20 upperintermediate foreign language students that pupils learn more vocabulary from captioned videos, in comparison with the no captions group. Indeed, there are some studies that report no difference between the use and nonuse of captions to accompany videos (e.g. Yuksel and Tanriverdi, 2009). Importantly, to the author's knowledge, there is no scientific study to confirm the harm of captioned videos, as suggested by practitioners.

The main objection of tutors, however, is against the use of subtitles, as they supposedly hinder receptive skills development (Danan, 2004). However, subtitling has not been thoroughly researched, and the few empirical studies produce mixed and unconvincing results. For example, Pujolà (2002) investigated the use of subtitles as one possible help option for foreign language videos watching. Although his sample consisted of 22 English learners at beginner level, he divided them into four groups: from poor to high decoders. In the end, Pujolà stated that it was difficult to use the mixed results to draw conclusions. Nevertheless, he believed that higher-level decoders used subtitles as a listening aid, while for lower-level participants text aid was definitely needed. In a similar vein, Vulchanova, et al. (2015) divided their sample into three groups to study if subtitles, captions or nonuse of text help is most effective among EFL learners. They found only a marginal difference. To sum up, the widespread teachers' objection towards subtitles cannot be supported with empirical evidence.

Most recently, foreign language research puts the emphasis on mobile-assisted language learning (MALL) (e.g. Duman, Orhon and Gedik, 2014; Repetto, et al., 2021). It's advantages over CALL lie into the improved graphics and interaction opportunities, as well as greater accessibility of learning materials anytime and anyplace. Repetto, et al. (2021) studied the effects of immersive $360^{\circ}$ videos, and revealed that those with initial positive attitudes towards this technology greatly benefit from improved attention and learning new words. Overall, the scholars found a superior efficacy of $360^{\circ}$ videos, and those who were willing to use them outperformed students that watched standard non-immersive videos.

What made Web 2.0 so revolutionising for the use of videos in class, however, is the shift from user downloaded content to user generated content (Cinganotto and Cuccurullo, 2015). In other words, the role of videos has broadened from watching them to remixing them (Hafner, 2015). In 2008, Carney and Foss suggested that video production in the foreign language classroom is a fun and engaging technique to support course understanding and material memorisation. Abdulrahman and Basalama (2019) set out the aim to support this view with empirical data. The scholars engaged their sample of 25 EFL learners in collaborative production of a vocabulary video, using simple software like Windows Movie Maker. Results were promising, as the majority of participants enjoyed learning new words through the video project. Team work was a major source of enjoyment during the collaborative process. Most reported that they learned more, and were motivated for continuing efforts. Similarly, the methodology of Naqvi (2015) included digital video advertisements development. Findings indicated a positive impact of the elicited favourable emotional responses on the language skills development.

Diverse video-related exercises are available to foreign language teachers, but their adoption remains limited. Alabsi (2020) was 
among the few to demonstrate a more engaging use of videos in MALL. The scholar asked EFL learners to add subtitles to videos via mobile applications. Data showed effectiveness of the exercise to improve listening comprehension and sentence building skills. Moreover, the creativity of using mobile technology to produce video content brings excitement to the foreign language classroom and keeps students engaged (Alabsi, 2020).

\section{RAISED AWARENESS AND NEW UNDERSTANDING}

Videos have long been in use in foreign language teaching, and their benefits have been well studied. The discussion on empirical studies helped to gain new understanding about some wide-spread myths among teachers.

First, many argue that reading is better than watching videos for new vocabulary acquisition. However, empirical data reveals that effectiveness lies in the combination of text and video. It is arguably outdated to push students be passive text readers, when multimedia use is more emotional and attention-keeping, as well as less burdening (Mayer, 2002; Yadav, et al., 2011; Alley, et al., 2014).

Second, many instructors feel that video captioning and subtitling are harmful for comprehension and stimulate "laziness" among foreign language learners (Danan, 2004; Talavan, 2007). Indeed, research on subtitles as video aid produces mixed results. Still, there is scant, if any, empirical evidence to confirm the harm of captioning or subtitling. Moreover, captions are mostly found to help comprehension and vocabulary memorisation (Markham 1989; Garza, 1991; Chai and Erlam, 2008; Winke, Gass and Syodorenko, 2010). If there are inconsistencies in results, that is because the complexity of factors that comprise multimedia environments, and the even greater complexity of language learning itself.

Third, despite the popularity of videos as a supplementary tool in the foreign language teacher's toolbox, their use is fairly limited. It seems that practitioners are failing to exploit the full potential of Web 2.0. They mostly show expert-produced videos to pupils, instead of engaging them in collaboration and co-creation. With this rather passive use, teachers are missing out opportunities for greater enjoyment, motivation and knowledge acquisition (Naqvi, 2015; Abdulrahman and Basalama 2019; Alabsi, 2020).

Copyright () Authors

\section{POSSIBLE INTERVENTIONS}

The findings summarised in this research paper encourage practitioners to use videos in foreign language pedagogy. Captioning and subtitling might be debated among teachers, but science provides evidence that advantages outweigh disadvantages. The more intriguing question is how to use videos. The present report highlights two possible interventions.

First, context matters. Teachers should not use videos with text aid just for the sake of the medium. Instead, they need to identify the level and the needs of students. Academic studies suggest a link between language and skills levels and comprehension gains. Advanced level students are likely to greatly benefit from captions to close the listening - reading competence gap. On the other hand, beginners should be offered less complex video material, and subtitles may reduce the cognitive overload.

Second, professionals are encouraged to leverage the collaborative power of Web 2.0 and invite students in content co-creation. It was previously mentioned that youth today embraces the "remix culture", where various pieces are connected together to create something new (Hafner, 2015). In line with this thought, young learners are attracted by creating videos themselves with user-friendly Web 2.0 applications. It seems that teachers seldom offer such exercises in the foreign language courses, and this is an overlooked opportunity.

On the contrary, tutors may also decide to develop videos themselves to serve the needs of their foreign language training. While such audiovisual material will be tailored for the level of a specific audience, the process is timeconsuming for the teacher. Moreover, the benefits, if any, are mostly for the video creator, i.e. the teacher, and not for the audience, i.e. students, who are likely to passively consume content.

\section{CONCLUSION}

To conclude, the use of videos enhanced with captions or interlingual subtitles is a powerful Web 2.0 tool with proven effects on students' motivation and learning outcomes. However, practitioners are lagging behind technological developments and lack creativity, when offering videos in foreign language classes. To make the most out of videos, we need to be more open to experimentation, of 
course having in mind the class specifics, language and competency level.

The topic, however, is by no means exhausted. Given the restricted time frames, the present research report focused on the most relevant and freely available literature. Therefore, the study is limited in depth. More attention needs to be paid on other techniques for videos use in foreign language pedagogy, such as video annotations or vlogs creation. 


\section{REFERENCES}

Abdulrahman, T. R. and Basalama, N. (2019). Promoting students' motivation in learning English vocabulary through a collaborative video project. Celt: A Journal of Culture, English Language Teaching \& Literature, 19(1), 107-137.

Alabsi, T. (2020). Effects of Adding Subtitles to Video via Apps on Developing EFL Students' Listening Comprehension. Theory and Practice in Language Studies, 10(10), 1191-1199.

Alexander, B. and Levine, A. (2008). Web 2.0 Storytelling. Emergence of a New Genre. EduCAUSE Review, 43(6).

Alhamami, M. (2013). Observation of YouTube language learning videos. Teaching English with Technology, 13(3), 3-17.

Alley, S., Jennings, C., Persaud, N., Plotnikoff, R. C., Horsley, M. and Vandelanotte, C. (2014). Do personally tailored videos in a web-based physical activity intervention lead to higher attention and recall? An eyetracking study. Frontiers in Public Health, 2

Arndt, H. L. and Woore, R. (2018). Vocabulary learning from watching YouTube videos and reading blog posts. Language Learning \& Technology, 22(3), 124-142.

Bianchi, F. and Ciabattoni, T. (2008). Captions and subtitles in EFL learning: An investigative study in a comprehensive computer environment. EUT Edizioni Università di Trieste.

Canning-Wilson, C. (2000). Research in Visuals, Invited Paper for the Video Special Interest Group at the International TESOL. Arabia 2000 Conference, Hilton Ballroom, Hilton Hotel, April 12-14.

Canning-Wilson, C. and Wallace, J. (2000). Practical aspects of using video in the foreign language classroom. The Internet TESL Journal, 6(11), 36-1.

Carney, N. and Foss, P. (2008). Student Produced Video: Two approaches. English Teaching Forum, 2, 14-19.

Copyright (@) Authors
Caspi, A., Gorsky, P. and Privman, M. (2005). Viewing comprehension: Students' learning preferences and strategies when studying from video. Instructional Science, $33,31-47$.

Chai, J. and Erlam, R. (2008). The effect and the influence of the use of video and captions on second language learning. New Zealand Studies in Applied Linguistics, 14(2), 25-44.

Cinganotto, L. and Cuccurullo, D. (2015). The role of videos in the teaching and learning of content in a foreign language. Journal of e-Learning and Knowledge Society, 11(2).

Conole, G. and Alevizou, P. (2010). A literature review of the use of Web 2.0 tools in Higher Education. Available at: https://www.advance-he.ac.uk/knowledge-hub/literaturereview-use-web-20-tools-higher-education [Accessed 17 March 2021].

Danan, M. (2004). Captioning and subtitling: undervalued language learning strategies. Meta: Journal Des Traducteurs, 49(1), 67-77.

Duman, G., Orhon, G. and Gedik, N. (2014). Research trends in mobile assisted language learning from 2000 to 2012. ReCALL, 27(2), 197-216

Garcia Mayo, M.P. and Pica, T. (2000). L2 learner interaction in a foreign language setting: Are learning needs addressed ? International Review of Applied Linguistics, 38(1), 35-58.

Garza, T. J. (1991). Evaluating the use of captioned video materials in advanced foreign language learning. Foreign Language Annals, 24(3), 239-258.

Hafner, C. A. (2015). Remix culture and English language teaching: The expression of learner voice in digital multimodal compositions. TESOL Quarterly, 49(3), 486509.

Hanley, J. E., Herron, C. A. and Cole, S. P. (1995). Using video as an advance organizer to a written passage in the FLES classroom. The Modern Language Journal, 79(1), 57-66. 
Kabooha, R. and Elyas, T. (2015). The impacts of using YouTube videos on learning vocabulary in Saudi EFL classrooms. In ICERI 2015 Conference (pp. 3525-3531).

Markham, P. (1989). The effects of captioned television videotapes on the listening comprehension of beginning, intermediate, and advanced ESL students. Educational Technology, 29(10), 38-41.

Mayer, R. E. (2002). Multimedia learning. In Psychology of learning and motivation. Academic Press, 85-139.

Merkt, M., Weigand, S., Heier, A. and Schwan, S. (2011). Learning with videos vs. learning with print: The role of interactive features. Learning and Instruction, 21(6), 687704.

Mintel (2016). Mintel Teens' and Tweens' Technology Usage - UK, July 2016. Available at: http://store.mintel.com/teens-and-tweens-technologyusage-uk-july-2016 [Accessed 17 March 2021].

Mintel (2017). Teens' and Tweens' Technology Usage - UK - June 2017. Available at: https://reports-mintelcom.ezphost.dur.ac.uk/display/793343/ [Accessed 17 March 2021].

Mohsen, M. A. (2016). The use of help options in multimedia listening environments to aid language learning: a review. British Journal of Educational Technology, 47(6), 1232-1242.

Naqvi, S. (2015). Student created digital video and language learning: Voices from Omani classrooms. In Third 21st CAF Conference at Harvard, in Boston, USA, 6(1).

Pisarenko, V. (2017). Teaching a foreign language using videos. Social sciences, 6(4), 125.

Pujolà, J.-T. (2002). CALLing for help: Researching language learning strategies using help facilities in a webbased multimedia program. ReCALL, 14 (2), 235-262.

Repetto, C., Di Natale, A. F., Villani, D., Triberti, S., Germagnoli, S. and Riva, G. (2021). The use of immersive
360 videos for foreign language learning: a study on usage and efficacy among high-school students. Interactive Learning Environments, 1-16.

Tarchi, C., Zaccoletti, S. and Mason, L. (2021). Learning from text, video, or subtitles: A comparative analysis. Computers \& Education, 160, 104034.

Vulchanova, M., Aurstad, L. M. G., Kvitnes, I. E. N. and Eshuis, H. (2015). As naturalistic as it gets: subtitles in the English classroom in Norway. Frontiers in Psychology, 5, $1-10$.

Walthouwer, L. M. J., Oenema, A., Lechner, L. and De Vries, H. (2015). Comparing a video and text version of a web-based computer-tailored intervention for obesity prevention: A randomized controlled trial. Journal of Medical Internet Research, 17.

Winke, P., Gass, S. and Syodorenko, T. (2010). The effects of captioning videos used for foreign language listening activities. Language Learning \& Technology, 14(1), 65-86.

Yadav, A., Phillips, M. M., Lundeberg, M. A., Koehler, M. J., Hilden, K. and Dirkin, K. H. (2011). If a picture is worth a thousand words is video worth a million? Differences in affective and cognitive processing of video and text cases. Journal of Computing in Higher Education, 23, 15-37.

Yuksel, D. and Tanriverdi, B. (2009). Effects of watching captioned movie clip on vocabulary development of EFL learners. Online Submission, 8(2). 